Case Report

\title{
Squamou Cell Carcinoma Maxillary Sinus: A Case Report
}

\author{
Anjan Kumar Sahoo
}

Assistant Professor, Department of ENT, Department of ENT, Maulana Azad Medical College and Associate Hospital. New Delhi, India.

DOI: https://doi.org/10.24321/2349.7181.202012

\section{I $\quad \mathbf{N} \quad \mathbf{F} \quad \mathbf{O}$}

E-mail Id:

anjanvssmc@gmail.com

Orcid Id:

https://orcid.org/0000-0002-8073-6549

How to cite this article:

Sahoo AK. Squamou Cell Carcinoma Maxillary

Sinus: A Case Report. J Adv Res Med 2020; 7(2):

24-26.

Date of Submission: 2020-12-02

Date of Acceptance: 2020-12-20

\section{$\begin{array}{llllllll}\mathbf{A} & \mathbf{B} & \mathbf{S} & \mathbf{T} & \mathbf{R} & \mathbf{A} & \mathbf{C} & \mathbf{T}\end{array}$}

Carcinoma maxilla is generally an aggressive tumor, most commonly seen in elderly population. The disease has a high correlation with alcohol and tobacco consumption. Here we present a case of 55 years female with swelling in right cheek and right side nasal obstruction for last 8 month. Biopsy of the specimen confirms the diagnosis of squamous cell carcinoma of maxilla. Symptoms of maxillary sinus carcinoma can be nonspecific and may delay the diagnosis of same. This clearly draw the attention of careful history and detail physical examinations of suspicious cases for the timely management of the same.

Keywords: Maxillary Sinus, Squamous Cell Carcinoma, Cheek Swelling

\section{Introduction}

Maxillary carcinoma is relatively common in Asian continents. Primarily it arises from maxillary sinus (60-70\%) and from other sites like nasal cavity (12\%-25\%), ethmoid (10\%-15\%) and less than $1 \%$ from frontal and sphenoid sinuses. ${ }^{1}$ Squamous cell carcinoma is the most common cancer of maxillary sinus and mainly affects middle aged men with a male to female ratio $1.8: 1 .^{2}$ The incidence of of maxillary sinus cancer is around $0.2 \%$ and it represents $1.5 \%$ of all head and neck neoplasms. ${ }^{3}$

\section{Case Presentation}

A 55 years old female presented to ENT OPD with history of swelling in right side of cheek and right side nasal obstruction since last 8 month. On examination there was diffuse swelling of right cheek with obliteration of right naso-maxillary groove. The swelling was $5 \mathrm{~cm}$ to $7 \mathrm{~cm}$ in it's greatest dimension. There was complete obstruction of right side nasal cavity. Intra oral examination revealed loss of most of the right upper premolars and molars.
On nasal endoscopy there was a well defined ulcerated mass encroaching right lateral nasal wall, middle turbinate crossing to opposite side breaching the nasal septum. Computed tomographic scan of nose and para nasal sinuses showed mass in the right nasal cavity with bony destruction of anterior, lateral, medial wall of maxillary sinus and nasal septum and obvious invasion to pterygomaxillary fissure. There was also obliteration of all meati with destruction of nasal turbinates. Though there was destruction of floor of the orbit but tumour did not invade the periorbita (Figure 1). Incisional biopsy was taken from the mass under local anaesthesia which came to be moderately differentiated squamous cell carcinoma. She was got evaluated in head and neck cancer clinic and was prepared for right total maxillectomy. All the routine hematological, biochemical and routine radio logical investigations were done. After preanaestestic check up patient was posted for total maxillectomy under general anaesthesia(Figure 2 and 3). The tumor was removed in toto (Figure 4) and send for histopathological examination. 


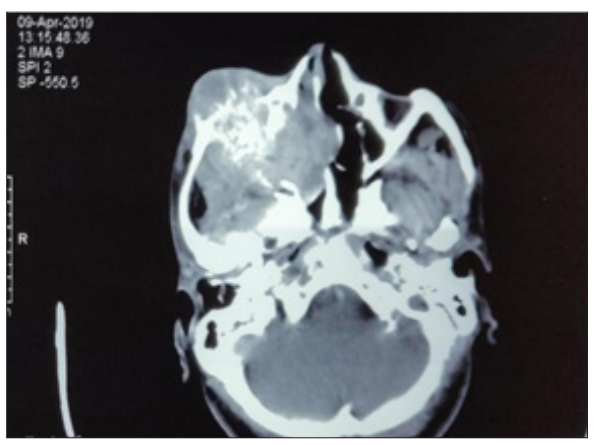

Figure I.Computed tomograpy of nose and Para nasal sinuses suggestive of complete destruction of right maxillary sinus suggestive of malignancy

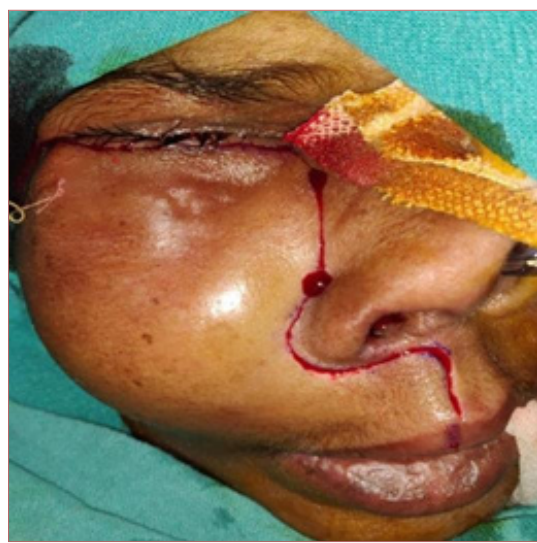

Figure 2.Incision for Right totalmaxillectomy

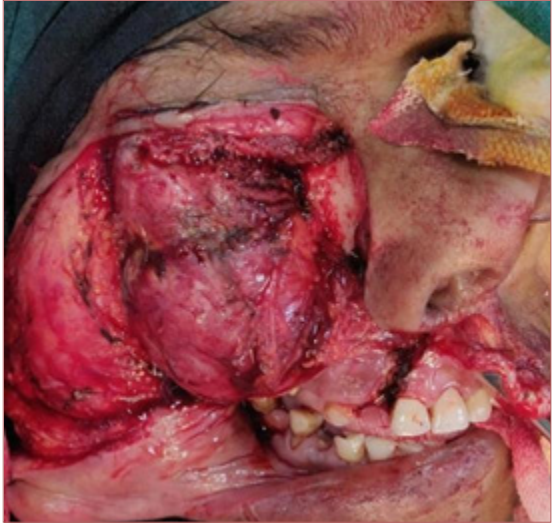

Figure 3.Tumor after elevation of Flap

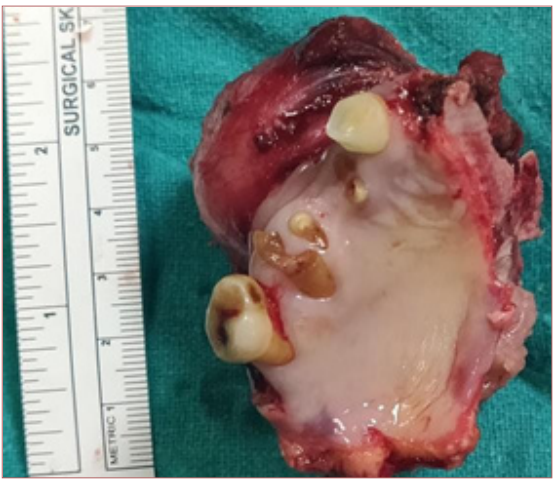

Figure 4.Resected Right Maxillectomy Specimen

\section{Discussion}

Cancer of the maxillary sinus is very rare entity. Approximately $3 \%$ of all head and neck cancers are form paranasal sinuses of which more than $50 \%$ origininates from maxillary sinus and out of which around $75 \%$ are squamous cell carcinomas. ${ }^{4}$ Cigarette smoking , exposure to nickel, formaldehyde, wood and textile dusts are the frequent risk factors for paranasal sinus malignancy. ${ }^{2,5}$ Nasal obstruction, epistaxis, headache, nasal discharge, facial pain, proptosis, palatal bulging, facial praesthesia, epiphora, loosening of tooth are the common symptons of caricinoma maxilla. Facial swelling and nasal obstruction are the prominent symptoms in our patient. As per literature the median time from onset of symptoms until diagnosis is around four months6, but it took around double time for our patient to be diagnosed. It may be because of air filled sinus cavities and deep position of the structures involved.

\section{Conclusion}

Carcinoma of nose and paranasal sinuses is relatively uncommon. Mostly it presents in an advanced stage because of availability potential space for the tumor to grow. Careful attention should also be given to the symptoms of these diseases, as mostly they are nonspecific and almost ignored by the patient in the early stage. Appropriate treatment planning with timely intervention can definitely improve the morbidity and mortality rates.

Conflict of Interest: None

\section{References}

1. Fukuda K, Kojiro M, Hirano M, Hyams VJ, Heffner D. Predominance of squamous cell carcinoma and rarity of adenocarcinoma of maxillary sinus among Japanese. Kurume Med J 1989; 36: 1-6.

2. urner JH, Reh DD. Incidence and survival in patients with sinonasal cancer: a historical analysis of populationbased data. T Head Neck 2012; 34: 877-885.

3. Nuñez F, Suarez C, Alvarez I, Losa JL, Barthe P, Fresno $M$. Sino-nasal adenocarcinoma: epidemiological and clinico-pathological study of 34 cases. J Otolaryngol 1995; 22: 86-96.

4. Myers LL, Nussenbaum B, Bradford CR, Teknos TN, Esclamado RM, Wolf GT. Paranasal sinus malignancies: an 18-year single institution experience. Laryngoscope 2002; 112: 1964-1969.

5. Roter M, Santos M, Paulo J, Servato S, Cardoso SV, Rogério De Faria P. Squamous cell carcinoma at maxillary sinus: clinicopathologic data in a single Brazilian institution with review of literature. Int J Clin Exp Pathol 2014; 7: 8823-8832.

6. Bradford TN, Teknos RM, Esclamado GT. Wolf Paranasal sinus malignancies: an 18-year single institution experience. Laryngoscope 2002; 112: 1964-1969. 